\title{
An analysis of energy diversification and transition trends in Africa
}

\author{
M. M. Akrofi ${ }^{1}$ (1) \\ Received: 2 October 2020 / Accepted: 6 November 2020 / Published online: 25 November 2020 \\ (C) Islamic Azad University (IAU) 2021, corrected publication 2021
}

\begin{abstract}
Unlike energy security, energy diversification, which is an essential precursor for energy security and sustainability transitions, has not received much scholarly attention, especially in Africa. Applying the Energy Mix Concentration Index method (a modified version of the Herfindahl-Hirschman Index), this study examined energy diversification and transition trends in Africa's top ten economies over an 18-year period, from 2000 to 2017. Data were obtained in July 2020 from the African Union Energy Commission's data portal. Overall, energy diversification was found to be occurring at a very slow pace. Kenya and Morocco emerged as the two most energy diversified countries (with indices of 0.34 and 0.37 , respectively), while Algeria (0.98) and Ethiopia (0.87) were the least diversified countries as at 2017. The energy transition trend is consistent with the multiple fuel use/energy stacking model rather than the energy ladder hypothesis. "Balance" (the share of each energy source in the energy mix) was found to significantly influence energy diversification. Contrary to past assertions, this study finds that higher "variety" (the number of energy sources in the energy mix) does not signify greater diversity. A weak negative linear relationship was found between gross domestic product growth and Energy Mix Concentration Indices for most countries, suggesting that as gross domestic product grows, the energy mix becomes more diversified. However, this relationship was statistically insignificant. Policy makers need to increase investments in renewable energies, and diversify their economies (especially in oil-dependent countries) to facilitate energy diversification and sustainable energy transitions.
\end{abstract}

Keywords Diversity $\cdot$ Economic growth $\cdot$ Energy security $\cdot$ Energy transition $\cdot$ Sustainability

\section{Introduction}

The energy mix of a country is an important determinant of its energy security, and it also has several implications for energy transition and climate policies (Rubio-Varas and Muñoz-Delgado 2019a). The United Nations Development Program (UNDP) defines energy security as the constant availability of energy in sufficient and affordable quantities without any adverse economic and environmental impacts (UNDP 2004). Energy security also includes the availability

The original online version of this article was revised: Figure 4 was incomplete.

Electronic supplementary material The online version of this article (https://doi.org/10.1007/s42108-020-00101-5) contains supplementary material, which is available to authorized users.

M. M. Akrofi

akrofi@student.unu.edu; macakrofi@gmail.com

1 Institute for the Advanced Study of Sustainability, United Nations University, Tokyo 150-8925, Japan and affordability of different energy resources, technology to harness these resources sustainably, and social acceptability (Tongsopit et al. 2016; Valdés 2018). On the other hand, energy diversification means introducing different energy sources into the energy generation mix and increasing the share of energy generated from each source to avoid a sole dependence on a single energy resource (Stirling 2010). Diversifying the energy mix/sources has been identified as a crucial strategy for achieving energy security (Vivoda 2019). According to Llerena and Llerena (1993), the rationale behind diversification is that "it is better to be exposed to several risks with limited consequences than to one risk where the probability of failure is weak, but that failure has unbearable consequences for the economies" (p. 230). Diversity, thus, ensures security in that, when one energy source fails, a country can depend on other energy sources to meet its needs. Energy diversification offers a preventative measure against shocks in the energy supply system, ensures adaptiveness in the face of uncertainties (Stirling 1999), and engender sensitivity to local and cultural contexts (Landau et al. 1996). 
Contrary to diversification is the concept of energy mix concentration, which is used as an indicator of vulnerability (Rubio-Varas and Muñoz-Delgado 2019a). Concentration occurs where a country depends heavily on a single or very few energy sources. Past studies have identified diversification as a precondition for decarbonization and GHG reductions (de Freitas and Kaneko 2011) as well as long-term sustainability (Templet 1999). Several international bodies, such as the United Nations and the European Union emphasize the need for diversity, especially by increasing investments in renewable energies to avoid costly GHG emissions from fossil fuels. As an important determinant of energy security, the place of diversification in developing regions such as Africa cannot be overlooked.

In Africa, where energy access is low, governments are faced with the challenge of meeting rising energy demand while ensuring the reliability and security of existing supply. The constant supply of affordable energy has long been identified as one of the most important strategies to alleviating poverty in Africa (IRENA 2016). Such a reliable supply is, however, dependent on the level of energy security, which is in turn influenced by diversity in the energy mix. Diversifying the energy mix in Africa, especially through investments in renewable energies will increase energy access, create employment, engender clean energy transitions, and ensure energy security. These benefits are intrinsically indispensable for the much-needed economic growth in the continent. Characteristically, the largest economies (in terms of GDP) in Africa are mostly endowed with oil resources, which contribute largely to their economic growth. Countries such as Nigeria, South Africa, Egypt, Algeria, Angola, amongst others, are all heavily dependent on oil for their economic growth. However, the global oil market is susceptible to various price shocks which usually takes a downturn on the economic growth of these countries.

Recent examples of these shocks include the COVID-19 pandemic, which has reduced energy demand and oil prices globally. Consequently, several studies (e.g. Kireyev 2020; Mania and Rieber, 2019; Matallah 2020) have focused on economic diversification in oil-rich countries where the focus is on diversifying domestic production and trade in order to avoid a sole dependence on oil exports. The World Bank Group (2019, p. 142) defines economic diversification as "the shift toward a more varied structure of domestic production and trade with a view to increasing productivity, creating jobs, and providing the base for sustained poverty-reducing growth." Clearly, the role of energy in such a process cannot be flouted since energy consumption in any form increases economic growth (Zafar et al. 2019). Energy is critical in production processes, transport, job creation, as well as poverty reduction. Hence, for a country to become economically diversified in its production and trade, a reliable and secure supply of affordable energy is an undeniable necessity.
However, unlike economic diversification, energy diversification has not received much scholarly attention. RubioVaras and Muñoz-Delgado (2019a) affirm that the diversification of energy mixes has not been studied from a long-term comparative perspective, especially using concentration indicators. Consequently, they analyzed long-term diversification and transition pathways for eight European countries (France, Germany, Netherlands, the United Kingdom, Spain, Italy, Portugal, and Sweden) with a focus on traditional forms of energy between 1800 and 2010. Lo (2011) examined supply and demand-side energy diversity in four Asian countries from 1987 to 2006 and found that their colossal dependence on oil-imports makes diversification difficult for these countries. Templet (1999) also studied energy, diversity, and development in economic systems. However, the study measured economic diversity based on the number of economic sectors using energy and the equitability of energy flows between them. As part of their study on strengthening the competitiveness of the national economy, Gorb et al. (2020) examined pathways for diversifying energy supply in rural Ukraine, and they identified biomass as the most promising renewable source for rural areas, while Allam (2020) identified energy diversification as a strategy for sustainability and resilience in megacities. Notably, none of these studies had a focus on Africa, thus, creating a geographic gap in the literature. Also, studies in which energy diversification indices are developed for the purpose of understanding transition pathways and comparisons across countries or regions, are somewhat limited, especially in Africa.

This study attempts to address these gaps by applying the Energy Mix Concentration Index (EMCI) (Rubio-Varas and Muñoz-Delgado 2019b) to examine the state of energy diversification and transition trends in ten of Africa's largest economies. The novelty of this study lies in the fact that it focuses on energy diversification rather than economic diversification, which has been the subject of many scholarly works on the continent. A quantitative indicator of the energy mix concentration is applied to energy data over an 18-year period (2000-2017), hence, providing comprehensive insights into the trends in energy diversification in Africa's largest economies over time. The study attempts to address three main questions: (1) Is energy diversification happening in Africa? (2) Does economic growth influence energy diversification in Africa? (3) What is the nature of the energy transition trends? The research was conducted over a period of 4 months, from June 2020 to September 2020. A theoretical framework for the study is presented in the ensuing section.

\section{Theoretical framework}

Recent technological advancement has made it possible to harness energy from different sources, hence, providing a great opportunity for energy diversification. However, the 
presence of various energy sources and technologies to harness them alone does not engender energy diversification. Several theoretical viewpoints have been advanced in an attempt to explain how new energy sources may be introduced into the energy mix. One of such theoretical perspectives is the energy ladder hypothesis. The hypothesis, which has traditionally been applied to households postulates that energy users tend to move to more sophisticated energy carriers as their socio-economic status improves (Hosier and Dowd 1987). Specifically, as income increases, the proportions of higher energy carriers also increases (Rubio-Varas and Muñoz-Delgado 2019a). Stern (2010) explains that high energy quality is characterized by more productive, cleaner, and flexible energy carriers. The energy ladder hypothesis assumes that both traditional and modern energy sources are available, and users tend to switch from traditional to modern sources as their income levels increase.

However, studies have shown that this process is more complex than it seems since users tend to rely on more than one energy source when their incomes increase, and better solutions become available (Hosier and Dowd 1987; Van Der Kroon et al. 2013). Hosier and Dowd (1987), for instance, found that even though households switched from wood to kerosene and electricity as their incomes increased, other factors such a household size, nature of the setting (urban/rural), and the perceptions of users about various fuel types were important determinants of their fuel choice. At the national level, the energy ladder hypothesis will imply that countries tend to switch to new/modern energy sources as their wealth increases. However, Rubio-Varas and MuñozDelgado (2019a) argued that diversification experiences vary by country and depend on their energy resource potentials and their level of energy consumption. Similar to the energy ladder hypothesis is the multiple fuel use model.

The multiple fuel use model, which is also known as "energy stacking" (Masera et al. 2000), equally associates energy transition to the socio-economic status of energy users. However, instead of the linear upward switch from traditional energy sources to modern ones as suggested by the energy ladder hypothesis, the energy stacking model postulates that households tend to use multiple energy sources as their income increases but not necessarily switching from one energy source to another (Harrington et al. 2020; Masera et al. 2000). Masera et al. (2000), for instance, found that households adopt additional technologies/fuel sources without abandoning the old one; hence, a complete switch from one energy source to another was unusual. They argued that this approach helped users to maximize energy security while benefitting from the advantages of each fuel source.

Harrington et al. (2020) asserted that the multiple fuel use model reflects user behavior in energy transitions more accurately than the energy ladder hypothesis, and it provides a good basis for effective policies to advance energy access. Major reasons why energy users may tend to stacking rather than switching include the unreliable nature of access to modern fuels, high cost of new appliances, and fuel price changes (Muller and Yan 2018). The high start-up costs of renewable energy (RE) technologies, for instance, has been one of the main factors associated with the slow pace of RE deployment in developing countries, especially in Africa. Even though the costs of RE technologies have been declining, a complete switch from conventional energy sources such as oil and natural gas to modern and clean energies is still not practical in many countries due to financial constraints and inadequate local expertise.

The leapfrogging hypothesis, however, challenges this status quo by postulating that low-income countries can expand their economies with modern low-carbon technologies without relying on conventional or fossil fuels as the advanced countries did (Gallagher 2006). This concept is based on the premise that modern and cleaner energy technologies can be transferred to, and widely deployed in developing countries. Gallagher (2006) contends that such technology transfer may not be practical, especially where the recipient developing countries lack the technological capabilities to develop or integrate/localize these technologies from the advanced countries.

The above perspectives demonstrate that energy diversification results from an interplay of several factors, and it can be a complex process. Even though the three theoretical perspectives above were primarily designed for energy transitions and not diversification, they clearly apply to this concept. Energy diversification implies making use of multiple energy sources. This entails harnessing new energy sources, which will require new technologies and investments. All three viewpoints (the energy ladder hypothesis, multiple fuel use model, and leapfrogging model) suggests that, with recent technological advancement, countries will be able to develop and introduce new energy sources, especially renewable energies into their energy mix. While the ladder hypothesis suggests that these new energy sources will replace traditional ones, the multiple fuel use model suggests that new energy sources may dominate the energy mix, but traditional energy sources will not be completely replaced. There is, however, little evidence to establish how such changes occur in different countries.

Past studies suggest that this process is influenced by the amount of energy consumed by a country, with lower energy-consuming countries being more likely to quickly diversify their energy mixes and achieve faster transitions than higher energy consumers (Henriques and Sharp 2016; Rubio \& Folchi, 2012). This study attempts to contribute to the body of evidence on the subject. Using GDP growth as a proxy, the relationship between diversity and wealth/ income of a country is tested. In the ensuing section, the 
methods adopted for the study, including the data sources and calculations are explained.

\section{Materials and methods}

This study examines energy diversification and transition dynamics in selected African countries over an 18-year period (2000-2017). Given the strong interest in economic growth and diversification, as outlined in the theoretical perspectives above, the study focuses on the countries with the largest economies in Africa. Countries included in the study were, thus, selected based on their gross domestic products (GDP). Top ten African countries in the World Bank's (2020) list of countries with GDPs for 2019 were selected for the study. These countries were: Nigeria, South Africa, Egypt, Algeria, Morocco, Ethiopia, Kenya, Angola, Ghana, and Tanzania in descending order of their GDPs. Data for the study were obtained from the African Union Energy Commission's (AFREC) energy data portal. ${ }^{1}$ AFREC is a specialized agency of the African Union (AU) under the Commission for Infrastructure and Energy, and one of its prime functions is to keep an up-to-date energy database for all African countries. Data on energy sources for electricity generation were extracted and used for measuring diversity in this study. Energy diversifications as used in this study, thus, relates to diversity in the electricity generation mix (hereafter referred to as energy mix) of the countries under study. The following steps were followed in assessing diversity among the countries.

Step 1 In measuring diversity, Stirling (2008) identifies three main properties: variety, balance, and disparity. Concerning electricity supply (which is the main focus of this study), diversity relates to the various categories of energy sources in the electricity generation mix (e.g., coal, nuclear, natural gas, etc.). Stirling (2008) asserts that the greater the variety of distinct energy sources in the energy mix, the greater the diversity, all things being equal. "Balance," on the other hand, refers to the proportion of each energy source in the energy mix. According to Stirling, the more even the balance across these energy sources in the mix, the greater the diversity, all things being equal (Stirling 2008). These two assertions about variety and balance are tested in this study. "Disparity" is the different nature and characteristics of each energy source (Rubio-Varas and Muñoz-Delgado 2019a). In this study, only the first two properties (diversity and balance) are considered. This is because disparity is a subjective and context-specific aspect of diversity (RubioVaras and Muñoz-Delgado 2019a). Rubio-Varas and MuñozDelgad (2019a) contend that as technologies and societies

\footnotetext{
${ }^{1}$ Available at https://afrec-energy.org/En/administration/index.php
}

evolve, the characteristics and the performance of energy sources change and consequently, the distance between a pair of options varies as their performance changes. Hence, it becomes impractical to include disparity in long term diversity analysis (Rubio-Varas and Muñoz-Delgado 2019a).

In this first step, various categories of energy sources in the electricity generation mix of each of the study countries were identified. These categories were readily available for each country on the AFREC database. In all, there were ten categories: Fuel oil, Gas/Diesel oil, Natural Gas, Coal, Nuclear, Hydro, Geothermal, Wind, Solar, and Biomass/ waste. These constitute "variety" as mentioned above. Data on each of these categories at the time of writing were available for an 18-year period from 2000 to 2017 on the AFREC portal. The amount of electricity generated from each source (for each year over the 18-year period) in megawatt-hours (MWh) was recorded for each country and used to determine the "balance." Hence, for each country, the proportion/share of each energy source in the energy mix was calculated by simply dividing the amount of electricity per source by the total amount of electricity from all sources in a particular year. Figures were expressed in fractions and not percentages for simplicity in applying the Energy Mix Concentration Index (EMCI) method. This method is explained below.

Step 2 The EMCI (Rubio-Varas and Muñoz-Delgado $2019 b$ ) is the primary method adopted for this study. It was developed based on the Herfindahl-Hirschman Index (HHI) (Rubio-Varas and Muñoz-Delgado 2019b). The HHI is a commonly applied metric in economics, often used to gauge the market concentration and competitiveness of an industry in terms of the size of each firm in relation to the industry. It is expressed as follows:

$$
H H I=\sum_{i=1}^{n}\left(S_{i}\right)^{2}
$$

where $S_{i}$ is the firm $i$ 's market share (Chang 2007; Laine 1995). The main advantage of these method is its simplicity and its lower data requirements. The method has been applied widely by scholars as well as government agencies such as the United States Justice Department (Laine 1995). As a measure of concentration, the HHI inherently measures diversity. Hence, a smaller HHI value (low concentration) indicates higher diversity and vice versa. HHI values range between 0 and 1 (that is when the share of each firm or industry is expressed as a fraction and not a percentage) where 0 indicates total diversity, and 1 indicates no diversity (total concentration). This method was used by Rubio-Varas and Muñoz-Delgado (2019b) to measure energy diversification in Europe, and they termed the resultant index, the Energy Mix Concentration Index (EMCI). The EMCI is the summation of the squares of the proportion of each energy 
Fig. 1 Number of energy sources in each country (a) and types of energy sources in each country (b) ( Source: Author's construct, created with Microsoft Excel)

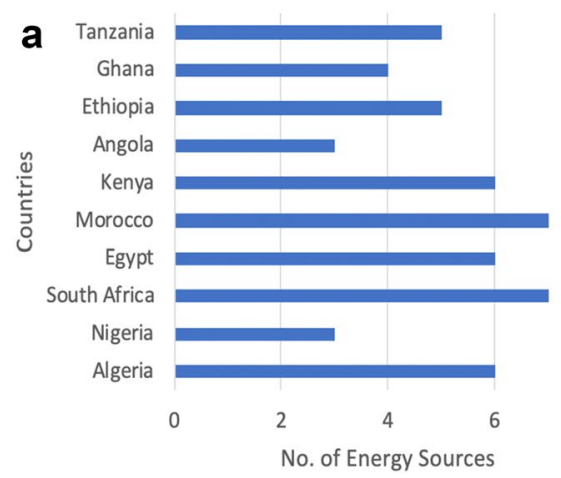

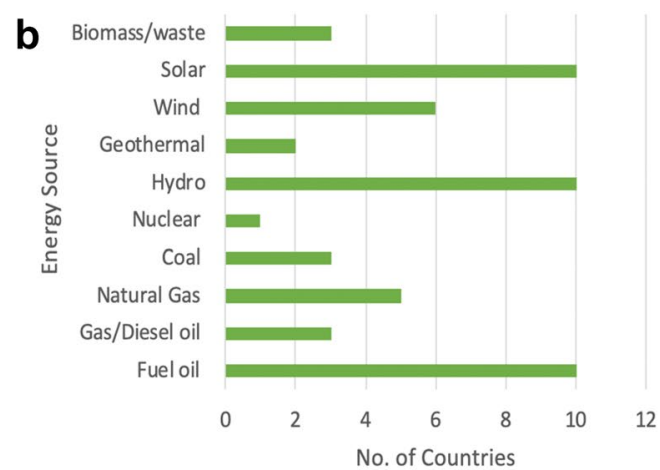

source in the energy mix in any given period (Rubio-Varas and Muñoz-Delgado 2019b). It is given by the formula:

$E M C I_{t}=\sum_{i}^{t} P_{i}^{2}$

where $P_{i}$ is the share of the energy source $i$ in the energy mix (Rubio-Varas and Muñoz-Delgado 2019b). Hence $i$ corresponds with the various energy sources identified in step 1 , that is fuel oil, gas/diesel oil, natural gas, coal, nuclear, hydro, geothermal, wind, solar, and biomass/waste. The share of each energy source, $P_{i}$ is expressed as a fraction in this study. In this step, the square of each share was taken for each energy source and summed up to arrive at the EMCI (see detailed calculations in Online Resource 1). This final step was also done yearly; hence, EMCI's were derived for each year from 2000 to 2017 (see Fig. 3). For the purpose of testing the relationship between income and diversity, the Pearson correlation test within the IBM SPSS package was used. Results from the analysis are presented in the ensuing section.

\section{Results and discussion}

This section begins with a brief description of the general characteristics of the energy mix in the countries studied, followed by a detailed analysis and discussions of the results of the study. Stirling's (2008) assertions about variety and balance and the relationship between wealth and energy diversification are also tested in this section.

\section{Characteristics of the energy mix in Africa's largest economies}

The energy mix of Africa's largest economies is characterized by a variety of conventional and non-conventional energy sources. Fuel oil, hydro, and solar are the most common sources of electricity generation, and they are found in the energy mix of all ten countries studied. Nuclear and geothermal are the least common, found in only South Africa and Kenya, respectively. South Africa and Morocco have the highest number of energy sources in their energy mix, with seven different sources each. Kenya and Algeria also have a high number of energy sources in their energy mix, with each of them having six different energy sources. Hence, these countries have a greater variety in their energy mix. Stirling's (2008) assertion will imply that these countries are highly diversified in terms of energy. This assertion will, however, be tested in the ensuing sections. Figure 1 shows the types and number of energy sources present in each country.

Fossil fuels continue to contribute the largest share of electricity in all the countries. The proportion of electricity generated from these sources each year ranges between $88.43 \%$ and $91.56 \%$ over the 18 -year period (see Fig. 2). Despite fluctuations in these proportions for the various years, the share of electricity generated from these sources appears to be decreasing in recent times. The proportion of electricity generated from fossil sources declined from $91.05 \%$ in 2015 to $88.83 \%$ in 2016 . Contrary to yearly changes observed for all previous years (before 2016), no change occurred in this proportion between 2016 and 2017; hence, the share of electricity generated from fossil fuels remained $88.83 \%$ in 2017 . However, the lack of data for 2018 and beyond made it impossible to determine whether or not this trend has changed. On the other hand, the share of electricity generated from renewable energy sources (including hydro) witnessed a $2.2 \%$ increase from 2015 to 2016, and the share of electricity from these sources remained the same for 2017 as well (see Fig. 1). Despite constituting an insignificant proportion of the total energy mix in the year 2000, the share of electricity generated from non-hydro renewables (solar, wind, geothermal, and biomass/waste) has witnessed a steady rise over the 18-year period. They became more noticeable in the energy mix in 2010 , contributing $0.85 \%$ of the total electricity generated in that year. This proportion has been on the rise and by 2017, the total electricity generated from non-hydro renewables constituted $2.94 \%$ of the total electricity produced in the ten countries. Unlike the shares 
Fig. 2 Shares of renewable and non-renewable energy sources in the energy mix of Africa's largest economies, 2000-2017 (It should be noted that the sum of shares in each year is more than $100 \%$ because, "All renewables" entail proportion of Hydro only + non-hydro renewables. The share of each category is calculated independently as a proportion of the total energy produced in each year). ( Source: Author's construct, created with Microsoft Excel)
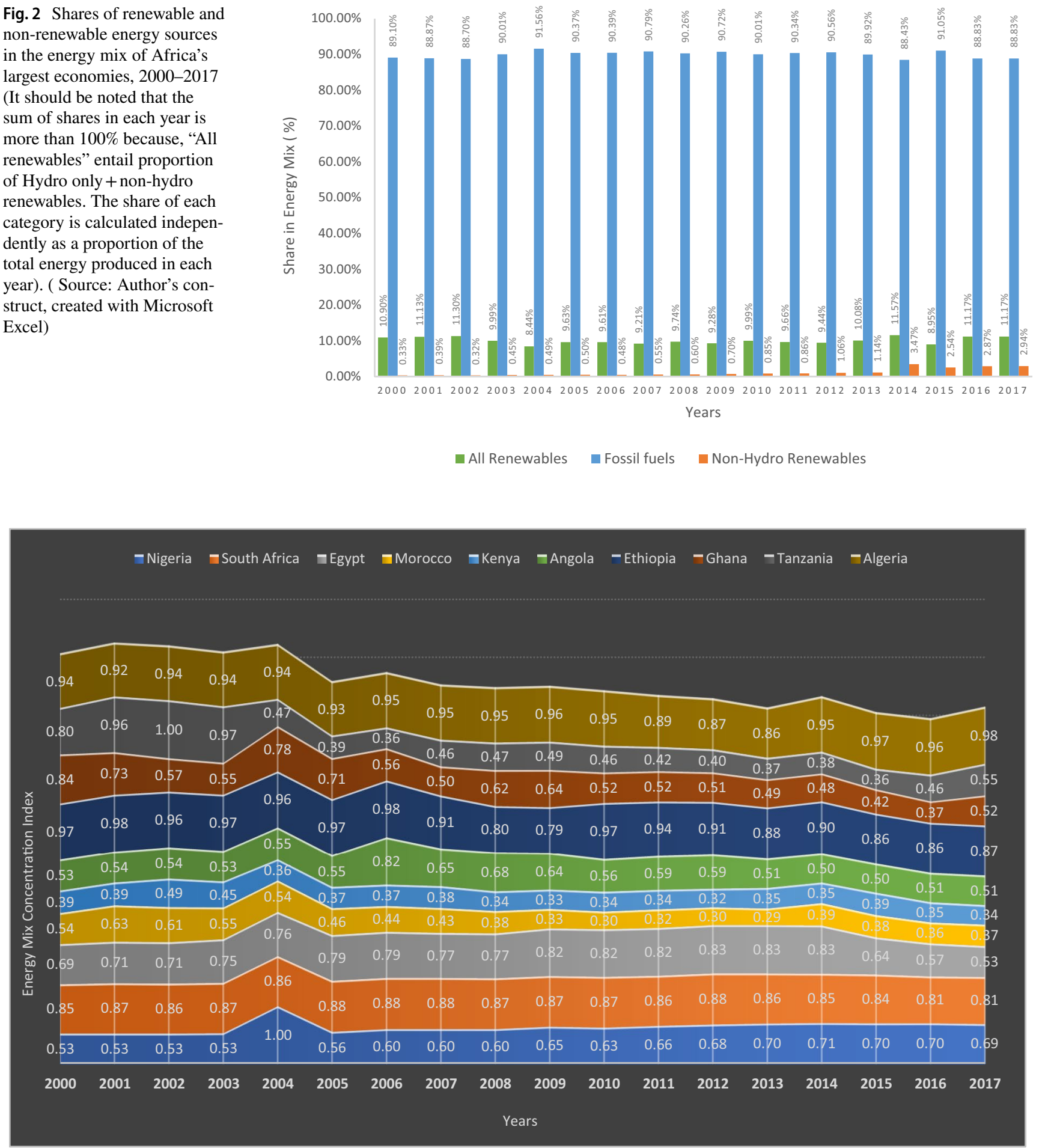

Fig. 3 EMCIs of various countries from 2000 to 2017 ( Source: Author's construct, created with Microsoft Excel)

from fossil fuels and all renewables (including hydro), which remained the same for 2016 and 2017, the percentage of electricity generated from non-hydro renewables witnessed a slight increase from $2.87 \%$ in 2016 to $2.94 \%$ in 2017.

\section{Status of energy diversification in Africa's largest economies}

Results from the EMCI analysis shows that energy diversification is gradually happening in Africa. The trends in 

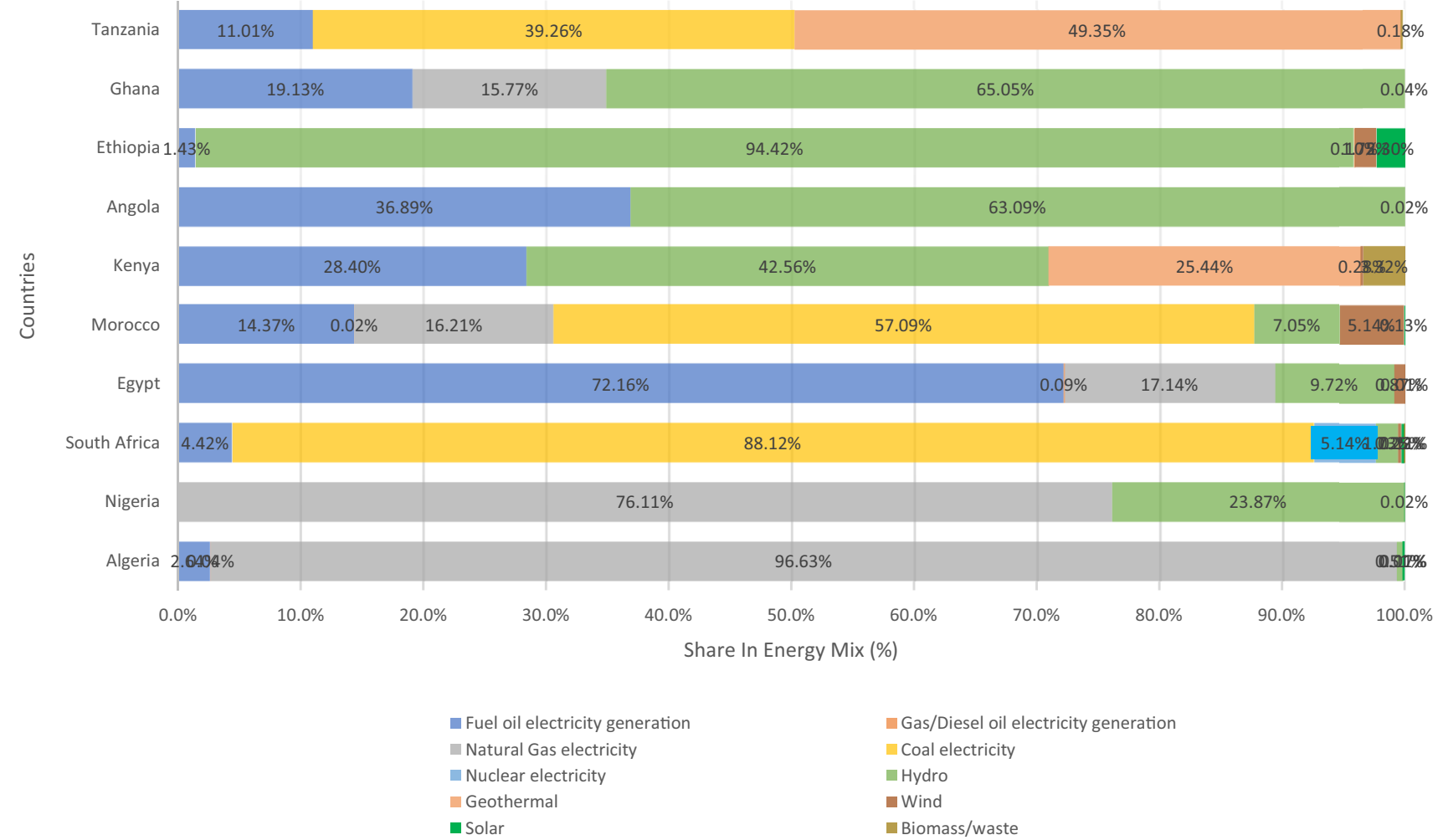

Fig. 4 Total shares of electricity generated from each source as at 2017 (Source: Author's construct, created with Microsoft Excel)

electricity generation from the sources identified indicates that overall, Africa's largest economies have moved from a relatively higher concentration in the early 2000 s towards increased diversity in recent times. However, the experience of each country varies as seen in Fig. 3. While some countries continue to diversify as at 2017 , others seem to be moving towards concentration. Countries such as Algeria, Tanzania, Ethiopia, and Morocco have witnessed slight increments in their EMCIs from 2016 to 2017. On the other hand, countries like Kenya, Egypt, and Nigeria continue to move towards higher diversification while South Africa and Angola have maintained the same levels for 2016 and 2017. Kenya is the most "energy diversified" country followed by Morocco, Angola, Ghana, Egypt, Tanzania, Nigeria, South Africa, Ethiopia, and Algeria.

Observably, Kenya and Morocco which emerged as the top two most diversified countries (with EMCIs of 0.34 and 0.37 , respectively) also have a wide variety in their energy mix, with six and seven different energy sources, respectively. However, the overall results suggest that variety does not necessarily guarantee diversity as postulated by Stirling (2008). This is because, countries like Algeria, South Africa, and Egypt also have high varieties in their energy mix (six, seven, and six respectively) yet, their energy mix is more concentrated with EMCIs of 0.98 for Algeria, 0.81 for South Africa and 0.53 for Egypt in 2017 as compared to
Kenya and Morocco. Also, with six energy sources, Kenya's energy mix is more diversified than that of Morocco which has seven energy sources. Angola and Ghana, which have three and four energy sources each are also more diversified than Tanzania and Ethiopia, which have five energy sources each. These results imply that variety in the energy mix does not signify energy diversification.

On the other hand, the share of each energy source (balance) in the energy mix engenders diversification. Countries with a more even distribution in terms of the share of each energy source in the energy mix tend to have lower EMCIs than countries where almost all electricity generation is from one source. From Fig. 4, it can be seen that two of the least diversified countries (Algeria and Ethiopia) have more than $90 \%$ of their electricity generation coming from only one source. In contrast, the two most diversified countries (Kenya and Morocco) have their proportion of electricity generated spread across different energy sources. This trend is observed for the rest of the countries. As one moves from the least diversified to more diversified countries, it can be seen that the proportion of electricity generated is more dispersed among the various sources in the energy mix. Figure 4 presents the total shares of each energy source in the energy mix for each country as of 2017.

The above finding affirms Stirling's (2008) assertion that all things being equal, the more even the balance across the 
energy sources in the mix, the greater the diversity. Balance in the energy mix is essential for energy security and it reflects Llerena and Llerena's (1993) viewpoint that being exposed to several risks with limited consequences is better than to one risk where failure will have negative impacts on the economy. Inferring from Fig. 4, if electricity generation from natural gas and hydro fails or gets interrupted in Algeria and Ethiopia, there will be severe consequences on the economies of these countries since more than $90 \%$ of their electricity is generated from these sources. Countries such as Nigeria, South Africa, and Egypt are also more likely to face the same problem given that more than $70 \%$ of their electricity comes from one source. The heavy reliance of these countries on oil poses a challenge to diversifying their energy generation mix. Lo (2011), for example, noted that the dependence on oil was a principal factor constraining energy diversification for some Asian countries.

These findings reflect the energy security status of each country, which was assessed by Azzuni and Breyer (2020) in their study of global energy security in which they computed energy security indices for all countries in the world. The most energy diversified countries were more likely to have higher energy security indices than the least diversified. Azzuni and Breyer's (2020) study shows that among Africa's largest economies, Kenya is the most energy secure country followed by Ghana, Morocco, South Africa, Tanzania, Egypt, Tunisia, Ethiopia, Algeria, and Angola. Even though the order of these countries in terms of energy security does not precisely match with the order of the countries in terms of EMCIs in this study; it could be seen that Kenya, Morocco, and Ghana which feature among the top five most energy diversified countries also appear among the top five most energy secure countries in Azzuni and Breyer's (2020) study. The absence of an exact match between the two is perhaps due to the fact that several other factors such as environment, cost, technological efficiency, literacy, culture amongst others were considered in the computation of the energy security indices by Azzuni and Breyer (2020).

\section{Does GDP growth influence energy diversification?}

All theoretical perspectives outlined in Sect. 1.1 suggest that wealth/income is an important driver of energy diversification. The theories postulate that once income increases, new and modern energy sources tend to be introduced in the energy mix. Burke (2013), for instance, found that economic development generally led to changes from the use of biomass to energy sourced from fossil fuels and then towards nuclear power and eventually renewables energies. Hence, countries with higher incomes can be expected to be more "energy diversified" than low-income ones. The results of this study, however, suggests that this assertion is not necessarily the case. Kenya and Morocco, which are the two
Table 1 Correlations between GDP growth and EMCIs of various countries

\begin{tabular}{lll}
\hline Country & Pearson correlation & Sig. (2-tailed) \\
\hline Nigeria & -0.140 & 0.581 \\
South Africa & $0.492^{*}$ & 0.038 \\
Egypt & -0.125 & 0.622 \\
Morocco & 0.214 & 0.393 \\
Kenya & -0.435 & 0.071 \\
Angola & 0.459 & 0.055 \\
Ethiopia & -0.203 & 0.418 \\
Ghana & -0.063 & 0.805 \\
Tanzania & -0.106 & 0.676 \\
Algeria & -0.085 & 0.738 \\
\hline
\end{tabular}

*Correlation is significant at the 0.05 level (2-tailed). Source: Author's calculations

most diversified among the ten countries, place 7th and 5th respectively in terms of GDP while Nigeria and South Africa which have the highest GDPs are among the least diversified countries. To test the relationship between GDP growth and energy diversification further, the Pearson correlation test within the SPSS package was used to correlate GDP growth rates $^{2}$ with the EMCIs of the various countries from 2000-2017. The results of this test are presented in Table 1.

Overall, no significant correlation was found between GDP growth and EMCIs. It should be noted that lower EMCI's indicate higher diversity (low concentration in the energy mix); hence, for GDP growth to drive energy diversification, the relationship between GDP growth rates and EMCIs must be inverse (negative). As seen in Table 1, the correlation coefficients from seven countries are negative. However, these coefficients are all too close to zero, implying a very weak correlation between GDP growth and energy diversification. Also, the alpha values from Table 1 show that overall, the relationship between GDP growth and energy diversification is statistically insignificant as all values for countries with negative correlation coefficients are greater than the significance level of 0.05 . A weak positive correlation was found between GDP growth and EMCIs for South Africa, Morocco, and Angola, implying that as their GDPs grow, their energy mix moves towards concentration and vice versa. South Africa's GDP growth rate, for instance, was 2.49 in 2013 with a corresponding EMCI of 0.85 . The GDP growth rate decreased to $1.85,1.19$, and 0.40 in 2014, 2015, and 2016, respectively. Correspondingly, the EMCIs were 0.85, 0.84, and 0.81. Even though the GDP growth increased to 1.41 in 2017, the EMCI remained the

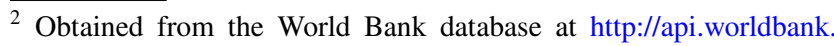
org/v2/en/indicator/NY.GDP.MKTP.KD.ZG?downloadformat=excel
} 


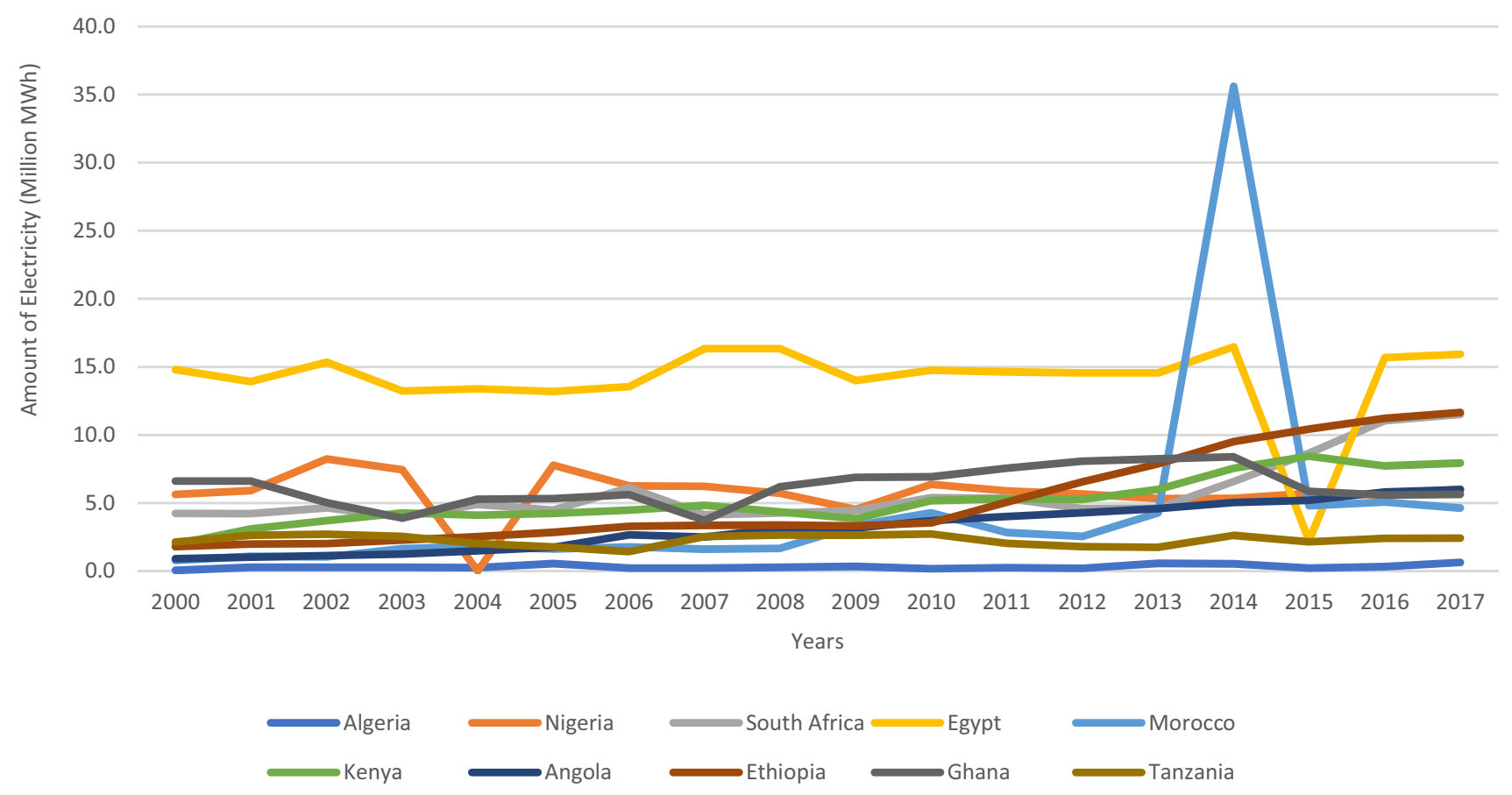

Fig. 5 Renewable energy generation trends from 2000-20,017 ( Source: Author's construct, created with Microsoft Excel)

same. Similar trends were observed for Morocco and Angola (see Online Resource 2 for details).

\section{Transition trends}

With regard to transition, the trend in RE growth, especially non-hydro renewables in the various countries reflect the multiple fuel use/energy stacking model rather than the energy ladder hypothesis and the leapfrogging concept. Inferring from Fig. 1, new forms of REs (non-hydro in particular) are increasingly gaining traction in the energy mix; however, conventional energy sources have not been replaced in the energy mix. Fossil-based sources continue to dominate in the energy mix, contributing the largest shares of electricity produced in all countries except Ethiopia, Ghana, and Angola where the majority of electricity generation comes from hydro (see Fig. 4). The trend of non-hydro REs continues to increase as of 2017. However, due to the absence of data beyond 2017 as of the time of writing, it is unclear whether the global peak in renewable energy investments in 2017 (Ajadi et al. 2019) has affected this trend. Key reasons why conventional energy sources dominate and perhaps, will continue to dominate the energy mix for the foreseeable future include the absence of highly efficient power systems which are economically sustainable and the high cost of infrastructure investments that are necessary for renewable energy penetration in the energy mix (Pistelli 2020). Even though renewable energies such as solar photovoltaics have become more competitive over the years, financial, technical, and managerial constraints still limit their largescale development in Africa (Azimoh et al. 2017; Pueyo 2018).

From Fig. 5, Algeria is the least performing country in terms of electricity generation from renewable (including hydro) energy sources. Haddoum et al. (2018) attribute this slow pace of renewable energy penetration in Algeria's energy mix to the country's heavy dependence on fossil fuels for economic growth and the huge amounts of subsidies paid to fossil fuel energy products by the government. They recommended that increasing investments in renewable energies and devising strategies to curtail the rising domestic energy consumption are important for energy transition in the country (Haddoum et al. 2018). The last part of this recommendation reflects Rubio and Folchi's (2012) assertion that higher energy-consuming countries are likely to transition over longer periods than lower energy consumers. For instance, it could also be seen in Fig. 5 that Ethiopia, which consumes much less energy than Algeria, has witnessed a constant rise in its renewable energy generation from 2010 to $2017 .{ }^{3}$ Similarly, Angola which is another smaller energy consumer as compared to Algeria, has since 2007 continued to witness a steady rise in its renewable energy generation while fluctuating trends can be observed in higher

\footnotetext{
${ }^{3}$ For data on energy consumption by country see World Bank's data portal at https://data.worldbank.org/indicator/EG.USE.ELEC. KH.PC?locations $=Z$ ZG-ZQ\&name_desc $=$ false
} 
consumers such as South Africa, Egypt, and Morocco. Observably, Morocco experienced a sharp rise in its renewable energy generation in 2014, adding 35612000MWh to its previous year's generation which was $4266000 \mathrm{MWh}$. This increment came mainly from additional capacities to hydro and wind energy sources (Oxford Business Group 2015).

\section{Conclusion}

Energy diversification is an important precursor for energy security and long-term sustainability transitions. Through energy diversification, Africa can increase its energy access rates, improve energy security, and environmental sustainability through the development of its vast renewable energy resources. The subject of energy diversification has, however, received little attention in the continent. This study is an attempt to shed light on the energy diversification situation and transition trends in Africa with a focus on the largest economies in the continent. Through an application of the EMCI method, the study finds that overall, Africa's major economies are gradually diversifying their energy mixes. Contrary to past assertions that the greater the variety of energy sources in the energy mix, the greater the diversity (Andy Stirling 2008), this study finds that higher variety does not signify greater diversity. Hence having numerous energy sources in the energy mix does not necessarily mean that the energy mix is diversified. However, the study affirms that "balance" (the share of each energy source in the energy mix) determines energy diversification. Countries with a more widespread or even distribution of the proportion of electricity generated across a range of sources were found to be more diversified than those in which the distribution of shares was highly skewed towards one energy source. Kenya emerged as the most "energy diversified" country followed by Morocco, while Algeria and South Africa were the least energy diversified countries.

With regard to the theoretical framework outlined in Sect. 1.1, a weak relationship was found between economic growth and energy diversification. From Fig. 3, it can be seen outright that Nigeria, South Africa, and Egypt which are the top three countries with the highest GPDs in Africa, are not the most diversified. Even though the correlation coefficients (see Table 1) from seven out the ten countries show that as GDP growth rates increases, the EMCIs tend to decrease, suggesting that GDP growth influences energy diversification, the relationship between the two is not statistically significant. In terms of transition, the general pattern of trend reflects the energy stacking/multiple fuel use hypothesis rather than the energy ladder and leapfrogging phenomenon. Even though the share of renewable energies continues to rise slowly in the energy mix; it is apparent that conventional energy sources are still dominant and are not being replaced as suggested by the ladder hypothesis. Also, the slow penetration of renewables in the energy mix implies that, African countries are not leapfrogging.

In light of the above findings, it is imperative for African governments to increase the share of energy generated from different sources, particularly renewable energies in their energy mix to achieve energy diversification and improve energy access and energy security. Such investments are also necessary for reducing carbon emissions from fossil fuel use which is essential for improved environmental outcomes. Policy decisions must focus on a paradigm shift from paying huge subsidies to fossil fuel energies to creating conducive market and regulatory environments for renewable energies. Policymakers must put in more efforts to build technical and managerial expertise locally to facilitate the deployment and utilization of renewable energies. Countries such as Algeria whose economic growth is dependent on oil and other fossil products must also pursue economic diversification policies and strategies to reduce their overdependence on fossil fuels. This situation has been identified as one of the main challenges to energy transitions (Haddoum et al. 2018).

\section{Limitations and recommendations for future research}

For the reliability and validity of data, the study used data from the African Union Energy Commission's database which at the time of writing, had data from the year 2000 to 2017. Hence, the analysis and findings made are limited to this time period. Data from 2018 to date would have provided an up-to-date picture of the energy diversification and transition trends in the countries studied. These data are particularly crucial for the energy transition trend, given that global renewable investments peaked in 2017. Data beyond 2017 would have helped to ascertain whether or not, this peak has affected the trend in renewable energy generation. The study also focused on the supply side of the energy equation for the same reason of data availability. However, demand-side factors are equally important for energy diversification and energy security (Solaymani 2020), and needs to be researched. Lo (2011), for instance, argued that diversity of demand-side is critical for an energy system because increasing the variety and balance of the energy users boosts efficiency and adaptability.

Acknowledgements The authors wish to thank all who assisted in conducting this work.

Funding No funding was received for conducting this study. 
Data availability All data generated or analyzed during this study are included in this published article and its supplementary information files.

\section{Compliance with ethical standards}

Conflict of interest The author has no relevant financial or non-financial interests to disclose.

\section{References}

Ajadi, T., Boyle, R., Strahan, D., Kimmel, M., Collins, B., Cheung, A., $\&$ Becker, L. (2019). Global trends in renewable energy investment 2019. Bloomberg New Energy Finance, 76. https://wedoc s.unep.org/bitstream/handle/20.500.11822/29752/GTR2019.pdf

Alley, I. (2018). Oil price and USD-Naira exchange rate crash: Can economic diversification save the Naira? Energy Policy, 118, 245-256. https://doi.org/10.1016/j.enpol.2018.03.071.

Azimoh, C. L., Klintenberg, P., Mbohwa, C., \& Wallin, F. (2017). Replicability and scalability of mini-grid solution to rural electrification programs in sub-Saharan Africa. Renewable Energy, 106, 222-231. https://doi.org/10.1016/j.renene.2017.01.017.

Azzuni, A., \& Breyer, C. (2020). Global energy security index and its application on national level. Energies, 13(10), 2502. https://doi. org/10.3390/en13102502.

Burke, P. J. (2013). The national-level energy ladder and its carbon implications. Environment and Development Economics, 18(4), 484-503. https://doi.org/10.1017/S1355770X13000090.

Chang, Y. (2007). The new electricity market of singapore: Regulatory framework, market power and competition. Energy Policy, 35(1), 403-412. https://doi.org/10.1016/j.enpol.2005.11.036.

de Freitas, L. C., \& Kaneko, S. (2011). Decomposing the decoupling of $\mathrm{CO} 2$ emissions and economic growth in Brazil. Ecological Economics, 70(8), 1459-1469. https://doi.org/10.1016/j.ecole con.2011.02.011.

Gallagher, K. S. (2006). Limits to leapfrogging in energy technologies? Evidence from the Chinese automobile industry. Energy Policy, 34(4), 383-394. https://doi.org/10.1016/j.enpol.2004.06.005.

Gorb, O., Rębilas, R., Aranchiy, V., Yasnolob, I., Boiko, S., \& Padalka, V. (2020). Strengthening competitiveness of the national economy by inhancing energy efficiency and diversifying energy supply sources in rural areas. Journal of Environmental Management and Tourism, 11(5), 1114-1123. https://doi.org/10.14505//JEMT. V11.5(45).09.

Haddoum, S., Bennour, H., \& Ahmed Zaïd, T. (2018). Algerian energy policy: Perspectives, barriers, and missed opportunities. Global Challenges, 2(8), 1700134. https://doi.org/10.1002/gch2.20170 0134 .

Harrington, E., Athavankar, A., \& Hsu, D. (2020). Variation in rural household energy transitions for basic lighting in India. Renewable and Sustainable Energy Reviews, 119, 109568. https://doi. org/10.1016/j.rser.2019.109568.

Henriques, S. T., \& Sharp, P. (2016). The Danish agricultural revolution in an energy perspective: A case of development with few domestic energy sources. The Economic History Review, 69(3), 844-869. https://doi.org/10.1111/ehr.12236.

Hosier, R. H., \& Dowd, J. (1987). Household fuel choice in Zimbabwe An empirical test of the energy ladder hypothesis. Resources and Energy, 9(4), 347-361. https://doi.org/10.1016/01650572(87)90003-X.
IRENA. (2016). Off-grid renewable energy in Africa. https://www.light ingglobal.org/wp-content/uploads/2016/03/20160301_OffGridSol arTrendsReport.pdf.

Kireyev, A. (2020). Diversification in the Middle East: From crude trends to refined policies. Extractive Industries and Society. https ://doi.org/10.1016/j.exis.2020.03.013 ((in press)).

Laine, C. R. (1995). The Herfindahl-Hirschman Index: A concentration measure taking the consumer's point of view. The Antitrust Bulletin, 40(2), 423-432. https://doi.org/10.1177/0003603x95 04000206.

Landau, R., Taylor, T., \& Wright, G. (1996). The Mosaic of Economic Growth. Stanford: Stanford University Press.

Llerena, D., \& Llerena, P. (1993). Diversity and valorization of the electricity-generation technologies in the European Community. Utilities Policy, 3(3), 223-232. https://doi.org/10.1016/09571787(93)90047-Z.

Lo, L.-H. (2011). Diversity, security, and adaptability in energy systems: a comparative analysis of four countries in Asia. World Renewable Energy Congress, 2401-2408. https://ep.liu.se/ ecp/057/vol10/016/ecp57vol10_016.pdf

Mania, E., \& Rieber, A. (2019). Product export diversification and sustainable economic growth in developing countries. Structural Change and Economic Dynamics, 51, 138-151. https://doi. org/10.1016/j.strueco.2019.08.006.

Masera, O. R., Saatkamp, B. D., \& Kammen, D. M. (2000). From linear fuel switching to multiple cooking strategies: A critique and alternative to the energy ladder model. World Development, 28(12), 2083-2103. https://doi.org/10.1016/S0305-750X(00)00076-0.

Matallah, S. (2020). Economic diversification in MENA oil exporters: Understanding the role of governance. Resources Policy, 66, 101602. https://doi.org/10.1016/j.resourpol.2020.101602.

Muller, C., \& Yan, H. (2018). Household fuel use in developing countries: Review of theory and evidence. Energy Economics, 70, 429-439. https://doi.org/10.1016/j.eneco.2018.01.024.

Oxford Business Group. (2015). Installed capacity rising to meet Morocco's growing energy demand | Morocco 2015 | Oxford Business Group. The Report. https://oxfordbusinessgroup.com/ overview/installed-capacity-rising-meet-moroccos-growing-energ $\mathrm{y}$-demand

Pistelli, L. (2020). Addressing Africa's energy dilemma. In M. Hafner \& S. Tagliapietra (Eds.), The Geopolitics of the Global Energy Transition (pp. 151-174). Springer International Publishing. https://doi.org/https://doi.org/10.1007/978-3-030-39066-2_7

Pueyo, A. (2018). What constrains renewable energy investment in Sub-Saharan Africa? A comparison of Kenya and Ghana. World Development, 109, 85-100. https://doi.org/10.1016/J.WORLD DEV.2018.04.008.

Rubio, M. D. M., \& Folchi, M. (2012). Will small energy consumers be faster in transition? Evidence from the early shift from coal to oil in Latin America. Energy Policy, 50, 50-61. https://doi. org/10.1016/j.enpol.2012.03.054.

Rubio-Varas, M., \& Muñoz-Delgado, B. (2019a). Long-term diversification paths and energy transitions in Europe. Ecological Economics, 163, 158-168. https://doi.org/10.1016/j.ecole con.2019.04.025.

Rubio-Varas, M., \& Muñoz-Delgado, B. (2019b). The Energy Mix Concentration Index (EMCI): Methodological considerations for implementation. MethodsX, 6, 1228-1237. https://doi. org/10.1016/j.mex.2019.05.023.

Solaymani, S. (2020). A demand-side assessment of sustainable energy security in Iran. International Journal of Energy and Water Resources, 4(3), 307-320. https://doi.org/10.1007/s42108-02000079-0.

Stern, D. I. (2010). Energy quality. Ecological Economics. https://doi. org/10.1016/j.ecolecon.2010.02.005. 
Stirling, A. (1999). On science and precaution in the management of technological risk: volume I - a synthesis report of case studies: Vol. I. European Commission Institute for Prospctive Technology Studies. http://ftp.jrc.es/EURdoc/eur19056en.pdf

Stirling, A. (2008). Diversity and sustainable energy transitions: Multicriteria diversity analysis of electricity portfolios. In M. Bazilian \& F. Roques (Eds.), Analytical Methods for Energy Diversity and Security (pp. 1-29). Elsevier Ltd. https://doi.org/10.1016/B9780-08-056887-4.00001-9

Stirling, A. (2010). Multicriteria diversity analysis. A novel heuristic framework for appraising energy portfolios. Energy Policy, 38(4), 1622-1634. https://doi.org/10.1016/j.enpol.2009.02.023.

Templet, P. H. (1999). Energy, diversity and development in economic systems; an empirical analysis. Ecological Economics, 30(2), 223-233. https://doi.org/10.1016/S0921-8009(98)00085-8.

Tongsopit, S., Kittner, N., Chang, Y., Aksornkij, A., \& Wangjiraniran, W. (2016). Energy security in ASEAN: A quantitative approach for sustainable energy policy. Energy Policy, 90, 60-72. https:// doi.org/10.1016/j.enpol.2015.11.019.

UNDP. (2004). World Energy Assessment, 2004 Update.

Valdés, J. (2018). Arbitrariness in multidimensional energy security indicators. Ecological Economics, 145, 263-273. https://doi. org/10.1016/j.ecolecon.2017.09.002.
Van Der Kroon, B., Brouwer, R., \& Van Beukering, P. J. H. (2013). The energy ladder: Theoretical myth or empirical truth? Results from a meta-analysis. Renewable and Sustainable Energy Reviews, 20, 504-513. https://doi.org/10.1016/j.rser.2012.11.045.

Vivoda, V. (2019). LNG import diversification and energy security in Asia. Energy Policy, 129, 967-974. https://doi.org/10.1016/j. enpol.2019.01.073.

World Bank Group. (2019). Economic diversification: lessons from practice. In OECD \& World Trade Organization (Eds.), Aid for Trade at a Glance 2019: Economic Diversification and Employment. OECD and WTO. https://doi.org/10.1787/888933953413

World Bank. (2020). Gross domestic product 2019. https://databank. worldbank.org/data/download/GDP.pdf

Zafar, M. W., Shahbaz, M., Hou, F., \& Sinha, A. (2019). From nonrenewable to renewable energy and its impact on economic growth: the role of research \& development expenditures in Asia-Pacific Economic Cooperation countries. Journal of Cleaner Production, 212, 1166-1178. https://doi.org/10.1016/j.jclepro.2018.12.081.

Zaheer, A. (2020). Sustainability And resilience in megacities through energy diversification, land fragmentation and fiscal mechanisms. Sustainable Cities and Society, 53, 101841. https://doi. org/10.1016/j.scs.2019.101841. 